\title{
Post-infarction cardiac remodeling-differential biomarkers for left atrial and left ventricular remodeling
}

\author{
Simina-Ramona Selejan ${ }^{1}$ (D) Mathias Hohl ${ }^{1}$. Michael Böhm ${ }^{1}$
}

Received: 26 April 2021 / Revised: 26 April 2021 / Accepted: 26 May 2021 / Published online: 4 June 2021

(C) The Author(s) 2021

Despite advances in myocardial infarction (MI) treatment, subsequent cardiac remodeling is still a relevant clinical problem. Post-infarction remodeling not only comprises left ventricular (LV) injury like scar formation, but also remodeling of the remote non-infarcted LV tissue and the left atrium (LA). The factors leading to atrial remodeling in MI are not well established. It is generally assumed that poor LV myocardial perfusion indirectly influences LA remodeling by causing LV dysfunction [1]. Still, relatively few pre-clinical and clinical studies take postinfarction atrial remodeling into consideration. Redondo et al. [2] took this additional step and investigated potential cardiac biomarkers for their usefulness in post-infarction remodeling for both left-sided heart chambers: Galectin-3 and sRAGE.

Galectin-3 is a lectin family adhesion molecule usually secreted from immune cells [3]. It is involved in various pathogenetic mechanisms promoting inflammation [4]. RAGE, the main receptor for advanced glycation end products (AGEs), is considered to not only be involved in diabetesassociated complications but a wide variety of diseases [5]. It is cleaved by metalloproteases to its soluble circulating form sRAGE, which has protective properties by binding and "neutralizing" AGEs [6]. Therefore, both Galectin-3 and sRAGE are circulating proteins easily measured in patient blood samples. Nonetheless, while Galectin-3 is regarded as a proremodeling factor, sRAGE is generally considered an antiremodeling agent [4-6].

In this issue of the Journal of Molecular Medicine, Redondo et al. [2] describe baseline Galectin-3 levels as predictors of adverse post-MI LV remodeling, while sRAGE levels exhibit an inverse beneficial relationship with LA

Simina-Ramona Selejan

simina.selejan@uks.eu

1 Klinik für Innere Medizin III, Universitätsklinikum des Saarlandes und Medizinische Fakultät der Universität des Saarlandes (Saarland University Hospital and Saarland University Faculty of Medicine), Saar 66421 Homburg, Germany remodeling 6 months after MI. Galectin-3 being an independent predictive factor for LV remodeling is consistent with previous reports [7]. However, sRAGE plasma levels demonstrating an inverse relationship with LA remodeling is a novel observation. What are the potential mechanistic explanations for those results? Mechanistic contributors are often potential biomarkers. Although not obvious at first glance, both investigated biomarkers are receptors for AGEs. Galectin-3 facilitates binding of AGEs to their receptor RAGE [8], thereby promoting inflammation. In contrast, sRAGE prevents RAGE activation by binding AGEs and "neutralizing" them $[5,6]$, thus suppressing tissue remodeling. Surprising is the observation that each of the two proteins is, apart from their principally opposite mode of action, a biomarker for only one of the two left heart chambers post-infarction. Galectin-3 enhances macrophage and mast cell infiltration into the infarcted myocardium propagating inflammation-induced fibrosis [4], which is the probable mechanistic explanation. Both Galectin3 and SRAGE however predict catheter ablation outcomes in atrial fibrillation without MI $[9,10]$, but only sRAGE is associated with atrial remodeling after MI [2]. AGE-sRAGE ratios being additionally directly related with LA enlargement, the assumption arises that AGEs could promote LA remodeling after MI and sRAGE could serve as decoy receptor counteracting AGEs [2]. Which leads to the question: Are AGEs differentially distributed in the heart after MI? Some evidence points to this. Despite the difficulty in obtaining human atrial tissue, it has been reported that AGEs levels are higher in the LA appendage of patients with atrial fibrillation than in controls [11] and that AGEs cause collagen crosslinking, which makes it difficult for collagenases to break down fibrosis [12]. At least one of the known AGEs, carboxymethyllysine (CML), accumulates in the atrium rather than in the ventricle after myocardial infarction [13], indicating that AGEs and sRAGE might play a greater role in atrial remodeling than in ventricular remodeling in this setting.

The present study adds another piece to the puzzle to the overall picture of MI-induced atrial and ventricular 
remodeling. Therefore, it might be worth investigating whether these two biomarkers might be actually indicating underlying mechanistic pathways. Sequential blood sampling would be important for the design of new studies, because it has already been shown that proteases such as MMP-9 are activated in acute MI and not only cleave RAGE and form sRAGE [6] but also degrade Galectin-3 [14], which somewhat diminishes the impact of early MI Galectin-3 and sRAGE levels with respect to their relevance for long-term remodeling.

Funding Open Access funding enabled and organized by Projekt DEAL. $\mathrm{MH}$ and $\mathrm{MB}$ are funded by Deutsche Forschungsgemeinschaft(ProjectID 322900939). MB reports personal fees from Abbott, Amgen, AstraZeneca, Bayer, Boehringer Ingelheim, Cytokinetics, Medtronic, Novartis, Servier, and Vifor.

Open Access This article is licensed under a Creative Commons Attribution 4.0 International License, which permits use, sharing, adaptation, distribution and reproduction in any medium or format, as long as you give appropriate credit to the original author(s) and the source, provide a link to the Creative Commons licence, and indicate if changes were made. The images or other third party material in this article are included in the article's Creative Commons licence, unless indicated otherwise in a credit line to the material. If material is not included in the article's Creative Commons licence and your intended use is not permitted by statutory regulation or exceeds the permitted use, you will need to obtain permission directly from the copyright holder. To view a copy of this licence, visit http://creativecommons.org/licenses/by/4.0/.

\section{References}

1. Ahn SG, Shin JH, Koh BR, Choi JH, Kang SJ, Choi BJ, Choi SY, Yoon MH, Hwang GS, Tahk SJ (2006) Impact of myocardial perfusion on left atrial remodeling following primary angioplasty for acute myocardial infarction. Coron Artery Dis 17(7):597-603

2. Redondo A et al (2021) Galectin-3 and soluble RAGE as new biomarkers of post-infarction cardiac remodeling. J Mol Med (Berl)

3. Yamaoka A et al (1995) A human lectin, galectin-3 (epsilon bp/ Mac-2), stimulates superoxide production by neutrophils. J Immunol 154(7):3479-3487
4. Zhong X, Qian X, Chen G, Song X (2019) The role of galectin-3 in heart failure and cardiovascular disease. Clin Exp Pharmacol Physiol 46(3):197-203

5. Kato $\mathrm{T}$ et al (2008) AGEs-RAGE system mediates atrial structural remodeling in the diabetic rat. J Cardiovasc Electrophysiol 19(4): 415-420

6. Selejan SR, Hewera L, Hohl M, Kazakov A, Ewen S, Kindermann I, Böhm M, Link A (2017) Suppressed MMP-9 activity in myocardial infarction-related cardiogenic shock implies diminished RAGE degradation. Shock. 48(1):18-28

7. Di Tano G et al (2017) Galectin-3 predicts left ventricular remodelling after anterior-wall myocardial infarction treated by primary percutaneous coronary intervention. Heart 103(1):71-77

8. Pricci F, Leto G, Amadio L, Iacobini C, Romeo G, Cordone S, Gradini R, Barsotti P, Liu FT, di Mario U, Pugliese G (2000) Role of galectin-3 as a receptor for advanced glycosylation end products. Kidney Int Suppl 77:S31-S39

9. Takemoto Y, Ramirez RJ, Yokokawa M, Kaur K, Ponce-Balbuena D, Sinno MC, Willis BC, Ghanbari H, Ennis SR, Guerrero-Serna G, Henzi BC, Latchamsetty R, Ramos-Mondragon R, Musa H, Martins RP, Pandit SV, Noujaim SF, Crawford T, Jongnarangsin K, Pelosi F, Bogun F, Chugh A, Berenfeld O, Morady F, Oral H, Jalife J (2016) Galectin-3 regulates atrial fibrillation remodeling and predicts catheter ablation outcomes. JACC Basic Transl Sci 1(3): 143-154

10. Yang P et al (2016) High plasma level of soluble RAGE is independently associated with a low recurrence of atrial fibrillation after catheter ablation in diabetic patient. Europace. 18(11):1711-1718

11. LeWinter MM et al (2017) Abundance, localization, and functional correlates of the advanced glycation end-product carboxymethyllysine in human myocardium. Phys Rep 5(20): e13462

12. Bi X, Song Y, Song Y, Yuan J, Cui J, Zhao S, Qiao S (2021) Collagen cross-linking is associated with cardiac remodeling in hypertrophic obstructive cardiomyopathy. J Am Heart Assoc 10(1):e017752

13. Begieneman MP et al (2016) Myocardial infarction induces atrial inflammation that can be prevented by $\mathrm{C} 1$-esterase inhibitor. J Clin Pathol 69(12):1093-1099

14. Ochieng J, Fridman R, Nangia-Makker P, Kleiner DE, Liotta LA, Stetler-Stevenson WG, Raz A (1994) Galectin-3 is a novel substrate for human matrix metalloproteinases-2 and -9 . Biochemistry. 33(47):14109-14114

Publisher's note Springer Nature remains neutral with regard to jurisdictional claims in published maps and institutional affiliations. 